\title{
Pathogenicity of entomopathogenic fungi against white grub, Leucopholis lepidophora (Blanchard) infesting sugarcane under pot culture experiment
}

PRADNYA B. MANE* AND PANDURANG B. MOHITE

Division of Entomology, Mahatma Phule Krishi Vidyapeeth, College of Agriculture, KOLHAPUR (M.S.) INDIA

\begin{tabular}{lll} 
ARITCLE INFO \\
\hline Received & $:$ & 02.08 .2014 \\
Revised $\quad:$ & 14.01 .2015 \\
Accepted & $:$ & 29.01 .2015 \\
\hline
\end{tabular}

KEY WORDS :

Metarhizium anisopliae, Beauveria brongniartii, B. bassiana, Leucopholis lepidophora, Sugarcane

*Corresponding author: Email: pradnyamane03@gmail.com

\begin{abstract}
The pathogenicity of entomopathogenic fungi, Metarhizium anisopliae (Metsch.) Sorokin, Beauveria brongniartii (Sacc.) and Beauveria bassiana (Balsana) Vuillrmin, was done against white grub, Leucopholis lepidophora (Blanchard) infesting sugarcane under pot culture experiment. In this investigation the virulence of different entomopathogenic fungi were determined by FYM enriched techniques against third instar grubs of Leucopholis lepidophora (Blanch.).An overall concentration range of $2 \times 10^{4}-2 \times 10^{8}$ conidia $\mathrm{ml}^{-1}$ of entomopathogenic fungi were used but among these, $2 \times 10^{8}$ conidia $\mathrm{ml}^{-1}$ concentration was the most promising for highest grub mortality in each entomopathogenic fungi. $M$. anisopliae was found to be most effective fungus as compared to other fungi. It was observed that 34.49-62.07 per cent grub mortality occurred on 45 DAT in $M$. anisopliae at different conidial concentrations. B. brongniartii recorded 31.03 to 58.62 per cent grub mortality while, $B$. bassiana caused 27.59 to 55.18 per cent grub mortality at different conidial concentration. The results showed that $M$. anisopliae was found to be more pathogenic than B. brongniartii and B. bassiana.
\end{abstract}

How to view point the article : Mane, Pradnya B. and Mohite, Pandurang B. (2015). Pathogenicity of entomopathogenic fungi against white grub, Leucopholis lepidophora (Blanchard) infesting sugarcane under pot culture experiment. Internat. J. Plant Protec., 8(1) : 41-44. 